\title{
Operational Challenges of the Bangkok Airport Rail Link
}

\author{
Waressara Weerawat $^{1,2}$ (1) $\cdot$ Lalitphan Samitiwantikul $^{1} \cdot$ Ratthanan Torpanya $^{1}$
}

Received: 21 June 2019/Revised: 15 November 2019/Accepted: 9 December 2019/Published online: 25 January 2020

(C) The Author(s) 2020

\begin{abstract}
The airport rail link (ARL) was launched in 2010 as a premium rail transit service between the inner city of Bangkok and the airport. In 2014, the express service was canceled due to its unpopularity and transformed into the commuter service. In 2017, the new extended service concept was introduced under the three airport links project. Under this new concept, both ARL and high-speed trains will run on the city line section between Don Mueang and Suvarnabhumi Airports. This paper focuses on the use of a microsimulation model to identify the challenge of mixed-service operations, with regular and express trains running on the city line section. The simulation model allows investigation of hypothetical situations and construction of feasible timetables. The model can identify sections where special attention is needed, such as speed reductions, extended dwell times, or delayed departures. During the peak hour, the results suggest that the regular ARL should run with a 10-min headway and the highspeed one line with a 20-min headway, as an alternative solution. This results in fewer train numbers and less additional running time. Simulations indicate that the highspeed train is not efficient, as it consumes 2-3 times higher energy, while offering little time saving compared with the ARL city train. In addition, the Suvarnabhumi Airport
\end{abstract}

Waressara Weerawat

waressara.wee@mahidol.ac.th

1 Department of Industrial Engineering, Faculty of Engineering, Mahidol University, Phutthamonthon, Nakhonpathom 73170, Thailand

2 Cluster of Logistics and Rail Engineering, Faculty of Engineering, Mahidol University, Phutthamonthon, Nakhonpathom 73170, Thailand

Communicated by Marin Marinov. extension track layout needs to be carefully considered, since the Suvarnabhumi Station area is a bottleneck liable to disruption.

Keywords Bangkok airport rail link · Rail timetable planning $\cdot$ Rail network $\cdot$ Rail Simulation

\section{Introduction}

\subsection{Airport Rail Link}

The airport rail link (ARL) is a train service that carries passengers between the city of Bangkok and the airport, which is located on the outskirts of the city. Many major cities, especially in developed countries, have airport link services by train as part of their public transportation systems: either a direct or indirect service. The direct service often runs as an express train between the airport and the city center area, with plenty of seating capacity and large luggage storage areas; For example, London Heathrow Express, Hong Kong Airport Express, or JR Narita Express in Tokyo can be regarded as direct services [1-3]. This type of service is regarded as a premium service, where guarantee options might be offered in cases of delay. The service guarantee for the Heathrow Express service in London entitles passengers to $100 \%$ compensation if the train is delayed more than $30 \mathrm{~min}$. With this guaranteed service, passengers can feel more confident using the train connection to the airport, even if its price is higher than the nonairport link route.

For an indirect service, the airport station is often part of a wider network, which can be either a metro, a commuter, or an intercity line. A train stopping point is normally located at the airport facility or a nearby building, as it is 
comparable to the use of the regular train services. Examples of indirect services offered with airport routes include London Heathrow Airport, served by the Piccadilly Line, or Frankfurt Airport, served by S-bahn commuter lines, regional express lines, and intercity express lines $[1,4]$.

The ARL in Bangkok was built and operated as a premium service since 2010 . Originally, there was a city terminal where passengers could check in. The train had one dedicated carriage for luggage shipments. In 2014, the express service was canceled due to the lower than expected numbers of direct airport passengers and the poor reliability of train sets [5]. About 80,000 passengers now use the ARL daily, with around 5500 trips per direction during the morning peak hours. The ARL now serves as a commuter line which is crowded during peak hours. This current ARL service is considered to be popular as a commuter line because of the heavy traffic problems for the city of Bangkok which makes bus transport an unattractive alternative. The current limitation of the ARL running headway results mainly from the limitation of the reliable car trains. The ARL operator has requested additional trains, so that they could offer a better passenger service. However, ordering of the additional train sets as well as infrastructure and rolling stock maintenance upgrades together with a new signaling system have been postponed due to a newly proposed merging concept of the ARL with the Eastern high-speed rail. With new service configurations, there will be many different train service types, such as regular ARL, express ARL, high-speed train 1 (HST-1), and high-speed train 2 (HST-2), using the same rail route. With the mixed service pattern and train configurations, it is a challenge to plan the timetable. This paper focuses on using a microsimulation model to identify challenges of mixed-service operations with regular and express trains running on the same line for the given service requirement. A simulation model of the ARL line has been developed to examine the operational difficulties and to identify route sections with special attention needed, such as speed reductions, extended dwell times, or delayed departures. Several different timetables have been constructed and evaluated iteratively using the microsimulation model.

The remainder of this manuscript is organized as follows. Section 1 is the brief overview about the airport rail link service in Bangkok and literature review on rail simulation modeling for rail timetable planning. Section 2 details the Bangkok airport rail link (ARL) with system characteristics and parameters. Next, Sect. 3 explains the methodology: simulation modeling. Section 4 presents analyses of results separated into single train simulation and network trains simulation. Finally, Sect. 5 presents conclusions of the work conducted in the paper.

\subsection{Rail Simulation Modeling}

In general, a rail timetable can be planned or adjusted to reflect the relevant passenger demand using analytical methods or simulation modeling. However, the analytical methods often have limitations in the case of complex railway networks with many interlocking areas [6]. Generic discrete-event simulation (DES) modeling is a well-known approach in solving complex rail timetabling and the traffic management problems of rail systems [7]. There are many commercial programs for both rail-specific simulation modeling (such as RailSys and Opentrack) and generic simulation modeling (such as Matlab, Simul8, and Arena). The rail-specific modeling programs are dedicated to railway applications. The programs often have built-in features to determine the speed from the train infrastructure and train configuration which align to the operational safety rules. The speed and position of each specific train set is based on the net result of tractive efforts and all resistances (such as vehicle and line resistances). The Davis, Strahal, and Sauthoff formulas are well-known train resistance equations that are often used in calculations $[6,8]$. For the safety functions of interlocking principles, the "blocking times" or "protected zone" concepts have been used in modeling train separation [9]. In the case of a generic simulation program, the applications are varied. The train movement equation may be simplified, or the running time estimation may be considered as an exogenous variable. The simple block concept may be used for allowing a single train at the station platform or between station areas.

There are examples in literature where generic simulation modeling was used to study urban passenger and freight systems. These studies often focus on the increased service performance and infrastructure utilization by modifying dwell time, departure time, headway, or dispatching rules [7, 10-13]. To increase the passenger service performance, the time performance indicators such as train delays (the deviation from the timetable), trip times, or passenger waiting times are evaluated among the different alternatives. Overall passenger trip time involves the waiting time, the dwell time for alighting and boarding, as well as the train running time. Variations in the trip time can be caused by a number of different factors, such as congestion and time-dependent passenger demand.

Comprehensive literature reviews about the methodological aspects of railway timetabling and simulation can be found in the paper "Railway timetabling and operations" [9]. The work by Bešinović [14] presents an extensive review section of rail specific simulations for all macro, meso, and microsimulation modeling depending on the detailed level of the infrastructure. The node and the link are the major components of railway infrastructure. Microsimulation incorporates the detailed infrastructure 
level which reproduces the functionality of interlocking, safety, and block systems. The detailed node-link of microscopic rail simulation models is composed of the main infrastructure information, such as track gradient, track radius, the station location, and the block length [15]. Many different route itineraries can be simulated at the same time in the synchronous microscopic model [16]. The output of simulation modeling, such as the travel time, can be displayed in the form of a graph or a table, which is easy to present and shows the overall result [17]. Several reseachers such as Keiji et al. [18], Ljubaj et al. [19], Pouryousef and Lautala [20] have used simulation modeling to address the operational challenges. Pitalänen and Capek [21], Botte and D'Acierno [22] used rail simulation modeling to show the effects of redesigning the track network, signaling, and turning points to improve track capacity. These also demonstrated the effects of train operating procedures, such as train movement patterns, stopping stations, and headway. The operations headway can be reduced by adjusting dwell time at the terminal station and turn-around time of the train [23]. With the unbalanced passenger usage between existing and extended lines, different short-loop operations can be introduced, and the performances can be evaluated using the simulation model [24]. In addition, the effects from rail system changes in terms of new train replacements, signaling types, network operations, and new passenger information systems, shown in simulation modeling, can reduce trip times significantly $[25,26]$. In comparing different simulation scenarios, several key performance indicators (KPI), such as trip time, number of trains, or number of stops at each station have been used.

\section{Case Study: Bangkok Airport Rail Link}

The airport rail link (ARL) provides an airport rail connection between Suvarnabhumi Airport and central Bangkok. ARL has a distance of $28.6 \mathrm{~km}$. It comprises eight stations: Suvarnabhumi (SVB), Lat Krabang (LKB), Ban Thap Chang (BTC), Hua Mak (HUM), Ramkhamhaeng (RKH), Makkasan (MAS), Ratchaprarop (RPR), and Phaya Thai (PTH). All stations in the network are elevated stations, except SVB, which is an underground station. This line connects with the Bangkok Metro Green Line at Phaya Thai Station and the Blue line at Makkasan Station.

The ARL was launched on 23rd August 2010 with the service between SVB and PTH. There were 5 trains for the city line service and 4 trains for the express line service. The service originally consisted of the city line, with a stop at every station and a journey time of $27 \mathrm{~min}$, and the express line, with stops only at SVB and MAS terminal stations and a journey time of $15 \mathrm{~min}$. On 1st June 2011, an additional express line service between PTH Station and the airport, with a journey time of $18 \mathrm{~min}$, was added. The express line service was suspended in September 2014 because of rolling stock shortage and lower than expected passenger numbers [5].

At present, ARL operates from 5:30 am to 12:00 pm for the city line and is served by nine trains. In peak times, there are headways of $8 \mathrm{~min} 30 \mathrm{~s}$, and $10 \mathrm{~min}$ off-peak. A short-term service is available in addition to normal operations, including HUM to PTH in the morning peak and PTH to SVB in the evening peak. After the ARL was launched, a feasibility study was carried out, and a design for a new airport rail link extension project (ARLEX) connecting Suvarnabhumi Airport and Don Mueang Airport was developed. This project is an extension from the existing ARL line at PTH Station. It has a distance of $21.5 \mathrm{~km}$ and two additional stations: Bang Sue Grand Station (BSE) and Don Mueang Station (DOM).

The high-speed railway Eastern line project is another initiative related to ARL. This project starts at LKB Station, a joint station with ARL, and ends at Rayong Station, with a total distance of $191 \mathrm{~km}$ and six stations. At present, there is a new project to connect three airports: Don Mueang Airport, Suvarnabhumi Airport, and U-Tapao Airport, in line with the Eastern Economic Corridor (EEC) Development Plan, which aims to connect Bangkok with three eastern provinces, namely Chachoengsao, Chonburi, and Rayong. The three airports project includes the two projects aforementioned and the existing ARL, with a total distance of $220 \mathrm{~km}$ and 15 stations. Currently, no track for the three airports link exists. Implementation of this project started in 2019, and operations are planned to begin in 2024 [27]. This is the first time the Thai Government has developed a high-speed rail project under the 50-year public-private partnership (PPP) program, with a net cost of around 224,544 million Thai baht [28].

Figures 1 and 2 illustrate the new three airports link project. It is expected to carry around 147,200 people per day using the modified airport link service: both city line and high-speed line [29]. During the first year of peak operation service, the high-speed section service frequency is expected to deliver around 1840 people per hour per direction (pphpd), while the ARL city line, or in-town section, is expected to deliver around 4670 pphpd.

\section{Methodology}

The future service plans of the airport extension lines were collected from various sources. There will be three main terminal stations at the three airports: Don Mueang (DOM), Suvarnabhumi (SVB), and U-Tapao (UTP). The operations service itinerary is summarized as shown in 


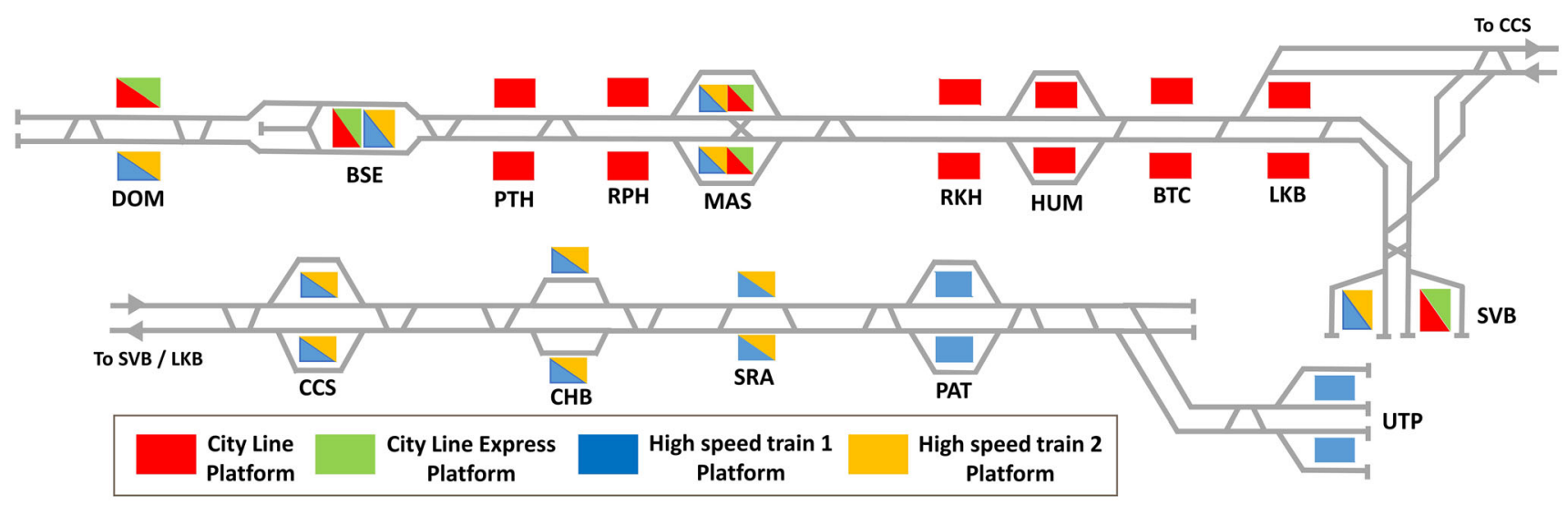

Fig. 1 Track outline of three airport project

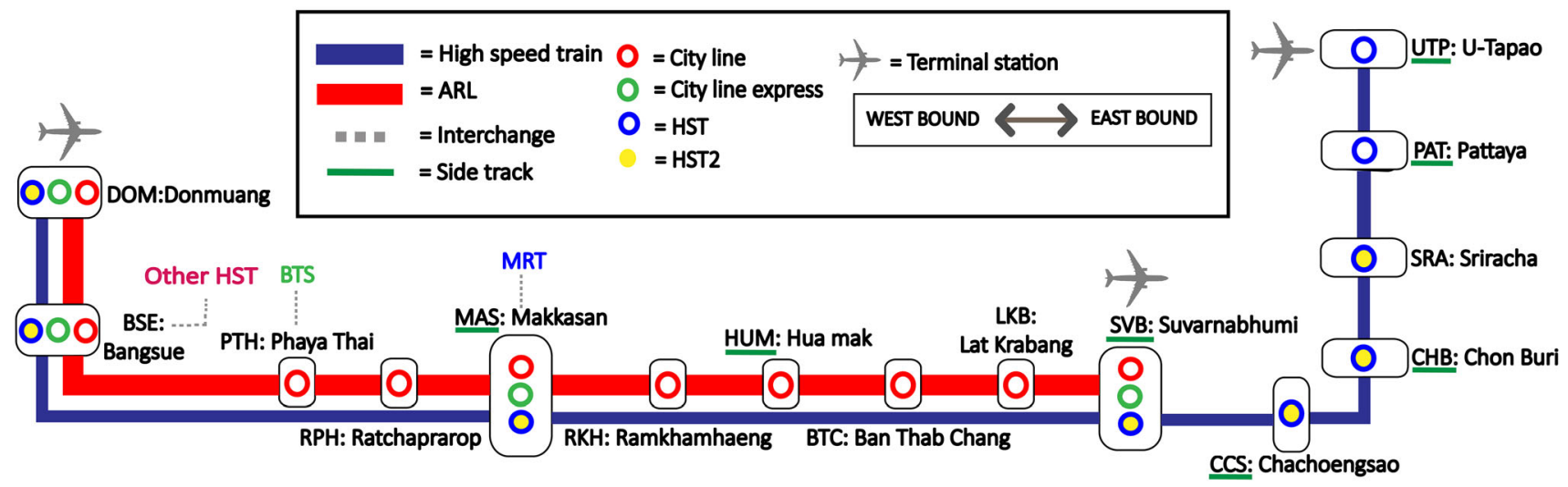

Fig. 2 Different rail services planned between three airports

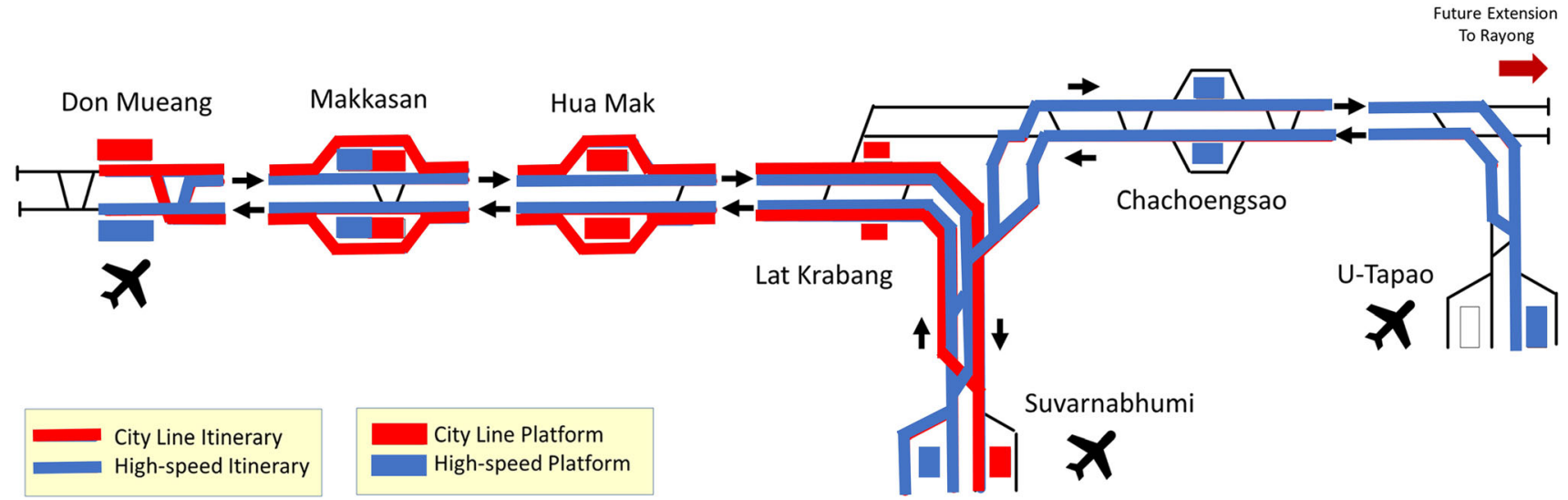

Fig. 3 Trip itinerary for city line and high-speed line

Fig. 2. With the mixed service pattern and train configurations, it is a challenge to plan for the timetable, especially for the in-town section between SVB and DOM. There are two stations where the faster train can pass over, but this pass over needs to be planned properly, so that it does not violate the safety rules regarding the spacing of the 2 trains following, as shown in Fig. 3.

The simulation model was built based on the given rail infrastructure information with the Opentrack version 1.9 software. In this study, two different types of train sets 
were used: the four-car Siemens Desiro and the eight-car Bombardier Zefiro, with the maximum train capacity of 1010 and 600 passengers, respectively. The Desiro is the existing train set that serves the in-town section, with a maximum speed of $160 \mathrm{~km} / \mathrm{h}$ and tractive force of $200 \mathrm{kN}$. The Zefiro is a newer train set, with a maximum tractive force of $366 \mathrm{kN}$. The Zefiro has a required speed of $250 \mathrm{~km} / \mathrm{h}$ for the out-of-town section. The new signaling plan was designed roughly with the maximum block length of $4 \mathrm{~km}$ for the out-of-town section and 500 meters for the in-town section. The signaling system was fixed block with a European train control system (ETCS) Level 2. All route sections for each train itinerary were reserved and released according to the safety principle of the signaling system. A different itinerary was set according to specific services, such as ARL city line, ARL city express, and high-speed lines. A single train and network trains simulation were modeled and run with several different scenarios.

In this paper, the trip time of the single train simulation was firstly investigated, especially for the in-town section, where much nonhomogeneous traffic occurs. For the single train simulation, both the ARL city train (Desiro) and the high-speed train (Zefiro) were used to run on the in-town express service section with four stopping stations to understand the base total running time. Then, the mixed traffic case was considered during both peak and off-peak hours for the network train scenarios.

For a feasible running scenario, there must be no conflict of "blocking time" from all train itineraries running in the same network. In rail operations, the "blocking time" refers to the occupied track section time during the train movement [6]. Trains can enter the track sections only with the movement authority from the control center or station master via a route setting request. Each train needs to receive the route reserving confirmation before it can proceed to the track sections. If there is any conflict in train running path or "route reserving" between two different trains, one of the two needs to wait. The following train can enter the track sections only after the first train has left the reserved track section and the occupied route has been released. In the network simulation, where there are many trains running in the network, it is possible that some trains need to wait before receiving the route reserving confirmation. The additional running time for all trains in the network can then be calculated by comparing the train trip time between the single and network models. The network timetable is then evaluated by comparing the total trip time used between the single train and network train models.

With the network train simulation, the three airports extension (DOM-SVB-UTP) was analyzed in order to understand the effects it will have at the terminal stations. However, the focus in this paper is mainly on the two airports extension (DOM-SVB), which is the in-town section where nonhomogeneous traffic occurs. Since construction of the two airport link sections (in-town section) is planned to be finished before the three airport link section (out-of town section), the high-speed train in-town section may need the city train or the existing Desiro train to run the express service during initial implementation. The $\mathrm{S} 1$ scenario is used herein to demonstrate this situation (Table 1). Scenarios S2 and S3 are based on the off-peak and peak service operations requirements. In addition, the $\mathrm{S} 4$ scenario is proposed as an alternative to the peak service operations requirement, since it requires fewer train sets and results in less additional running time. The summary of our simulation model is as follows (Table 1):

1. Single train simulation of in-town section (DOMSVB)

- ARL city line (all stops)

- Desiro or city train

- ARL express line (four stops)

- Desiro or city train

- Zefiro or high-speed train

2. Network train simulation

- In-town section (DOM-SVB) with maximum speed $160 \mathrm{~km} / \mathrm{h}$

- Desiro train: ARL city line

- Zefiro/Desiro train: ARL express line

- Out-of-town section (SVB-UTP) with maximum speed $250 \mathrm{~km} / \mathrm{h}$

- Zefiro train: high-speed line

\section{Results and Discussion}

\subsection{Single Train Simulation}

The interstation travel times of all train types based on the single train simulation model are summarized in Table 2 . In general, they rely on rolling stock types and station stopping patterns. This includes both total running time with and without dwell time at the stations. As shown in Table 2, the total running time of the Desiro express service (30:08 min:s) is less than the regular service (35:54 min:s), and the total running time or trip time of the Desiro express is more than the high-speed train (26:42 min:s) for the in-town track sections. This occurs because the maximum line speed can be reached only in the short period between each station (Fig. 4). However, 
Table 1 Scenario for network train simulation

\begin{tabular}{lllll}
\hline Scenario & \multicolumn{3}{l}{ Headway (min) } & \\
\cline { 2 - 5 } & Desiro city & Desiro express & Zefiro HST-1 & Zefiro HST-2 \\
\hline Itinerary & DOM-SVB & DOM-SVB & DOM-SVB-UTP & DOM-SVB-SRA \\
& SVB-DOM & SVB-DOM & UTP-SVB-DOM & SRA-SVB-DOM \\
S-1 (peak) & 12 & 12 & - & - \\
S-2 (off-peak) & 13 & - & 30 & - \\
S-3 (peak) & 13 & - & 30 & 20 \\
S-4 (peak) & 10 & - & 20 & - \\
\hline
\end{tabular}

Table 2 In-town section of three different rail services. Note: For the values of Express trains with (a) mark, they are the running times from first station to last station of each groups

\begin{tabular}{|c|c|c|c|c|c|c|c|c|}
\hline \multicolumn{3}{|c|}{ Eastbound (EB)—running time (min:s) } & \multirow[t]{2}{*}{ Interstation } & \multicolumn{2}{|c|}{ Distance $(\mathrm{km})$} & \multicolumn{3}{|c|}{ Westbound (WB)—running time (min:s) } \\
\hline City Desiro & Express Desiro & Express Zefiro & & City & Express & City Desiro & Express Desiro & Express Zefiro \\
\hline 07:40 & 08:02 & 07:11 & DOM-BSE & 13.87 & 13.62 & 07:47 & 07:54 & $06: 58$ \\
\hline $05: 36$ & \multirow[t]{3}{*}{ 07:12 (a) } & \multirow[t]{3}{*}{ 06:19 (a) } & BSE-PTH & 6.43 & 6.68 & $05: 37$ & \multirow[t]{3}{*}{ 07:05 (a) } & \multirow[t]{3}{*}{$06: 16$ (a) } \\
\hline 01:08 & & & PTH-RPR & 0.80 & 0.80 & 01:08 & & \\
\hline $02: 25$ & & & RPR-MAS & 2.14 & 2.02 & $02: 25$ & & \\
\hline $03: 19$ & \multirow[t]{5}{*}{$14: 54$ (a) } & \multirow[t]{5}{*}{$13: 12$ (a) } & MAS-RKH & 4.27 & 4.40 & $03: 18$ & \multirow[t]{4}{*}{$14: 42(a)$} & \multirow[t]{5}{*}{$12: 58(a)$} \\
\hline 03:49 & & & RKH-HUM & 4.91 & 4.91 & $03: 39$ & & \\
\hline 03:40 & & & HUM-BTC & 4.96 & 4.96 & $03: 40$ & & \\
\hline 04:05 & & & BTC-LKB & 6.23 & 6.23 & 04:05 & & \\
\hline $04: 22$ & & & LKB-SVB & 5.31 & 5.31 & $04: 38$ & $\downarrow$ & \\
\hline $35: 54$ & $30: 08$ & $26: 42$ & \multicolumn{3}{|c|}{ Trip time (no dwell time)—min:s } & $36: 17$ & 29:41 & $26: 12$ \\
\hline $39: 54$ & $32: 08$ & $28: 42$ & \multicolumn{3}{|c|}{ Trip time (with dwell time)—min:s } & $40: 17$ & $31: 41$ & $28: 12$ \\
\hline 381.45 & 307.54 & 794.68 & \multicolumn{3}{|c|}{ Energy consumption (kWh) } & 392.90 & 312.01 & 802.57 \\
\hline
\end{tabular}

the energy consumption of the high-speed train is about 2-3 times higher than the regular ARL Desiro train in this case.

\subsection{Network Train Simulation}

For the network train simulation, mixed trains were considered in one simulation run. As presented in Table 1, a total of four scenarios were analyzed in both eastbound and westbound directions. Due to the mixed service configurations, the numbers of train stops per hour (tph) can be different for each station. This is usually based on the service frequency at the peak and off-peak hours, and the station stops. With the different service configurations between the ARL regular and the ARL express service, the following train can overtake the preceding train (at MAS or HUM Stations). In order to avoid the conflict blocking times between two following trains, the following train may need to slow down. For the terminal stations, the arrival and departure trains from both eastbound and westbound directions may need to use the same block sections in order to turn around. In this case, one train must wait in order to prevent the conflict blocking times from the two trains from opposing directions. The slowdown and waiting can result in additional running time on some routes when compared with the single train simulation as the base case. Figures 5, 6, 7, 8 and 9 illustrate the timedistance diagram of the network train simulation during peak and off-peak services. Abbreviations in the figures such as EC1-3, EX1-4, WC1-3, and WX1-4 refer to different causes of additional running times in the network train simulation. Tables 3 and 4 summarize the additional running time needed for each type of service, which occurs mainly between Don Mueang (DOM) and Suvarnabhumi (SVB) terminal stations.

In these scenarios, the Desiro train runs on the ARL city line. The Zefiro train (or high-speed train) runs on the express line for both the in-town section (DOM-SVB) and out-of-town section (SVB-UTP). There are some delays and stops in the network simulation, especially for the intown section during the peak and off-peak periods, as follows. 

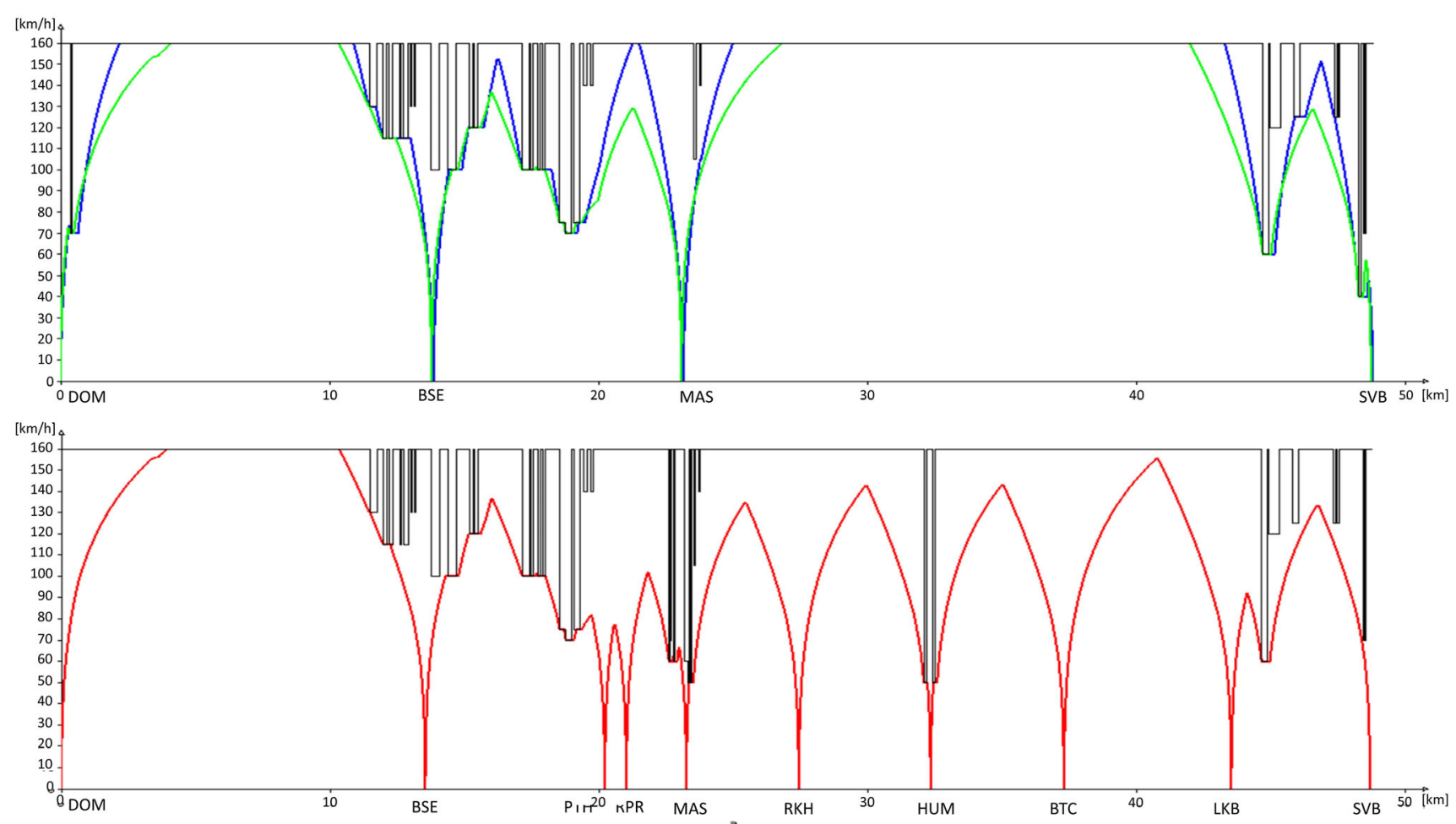

Fig. 4 Speed diagram for in-town section: Zefiro express (HST line-blue), Desiro city (red), Desiro express (green)

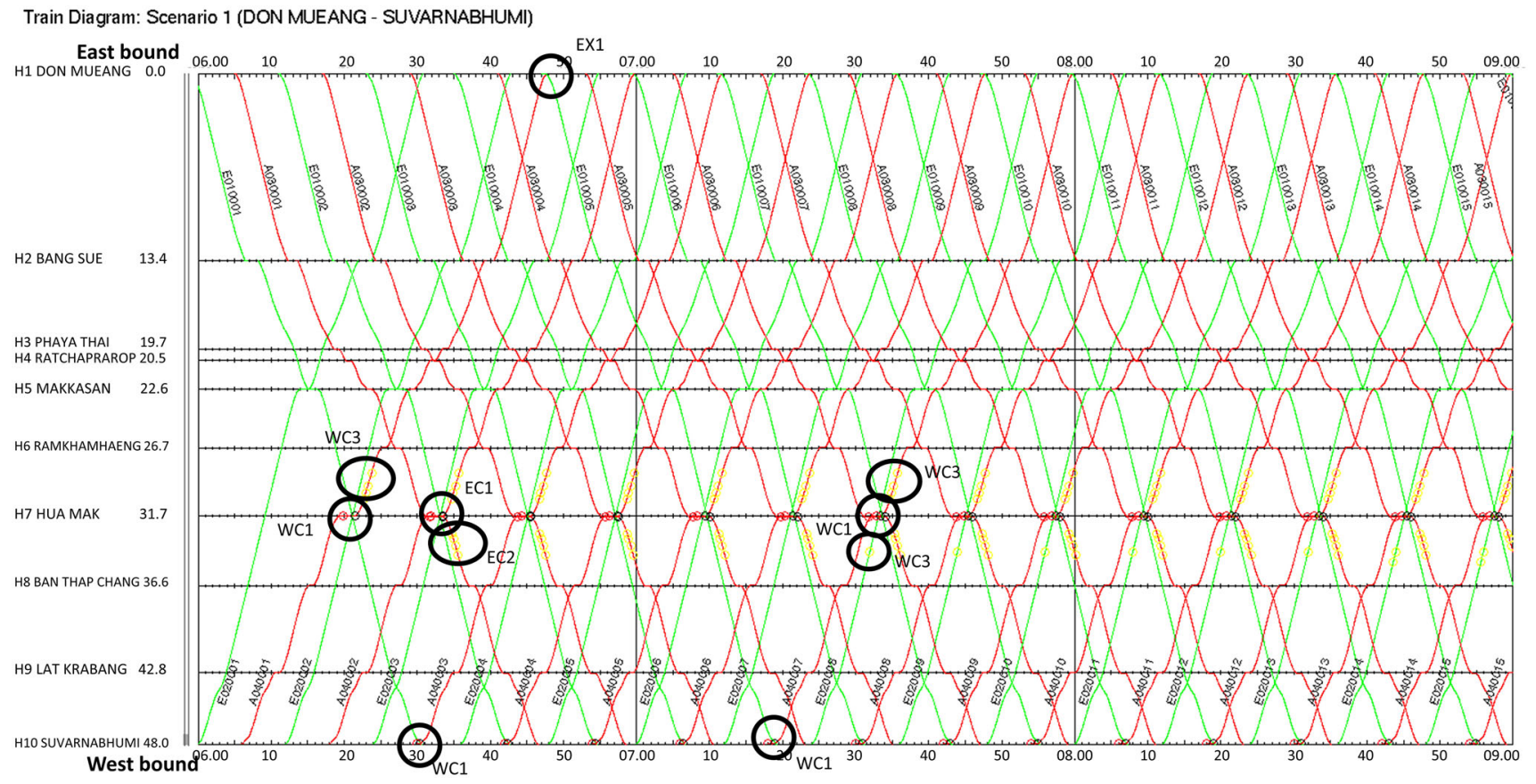

Fig. 5 Time-distance diagram of network train simulation for in-town service (S1) 


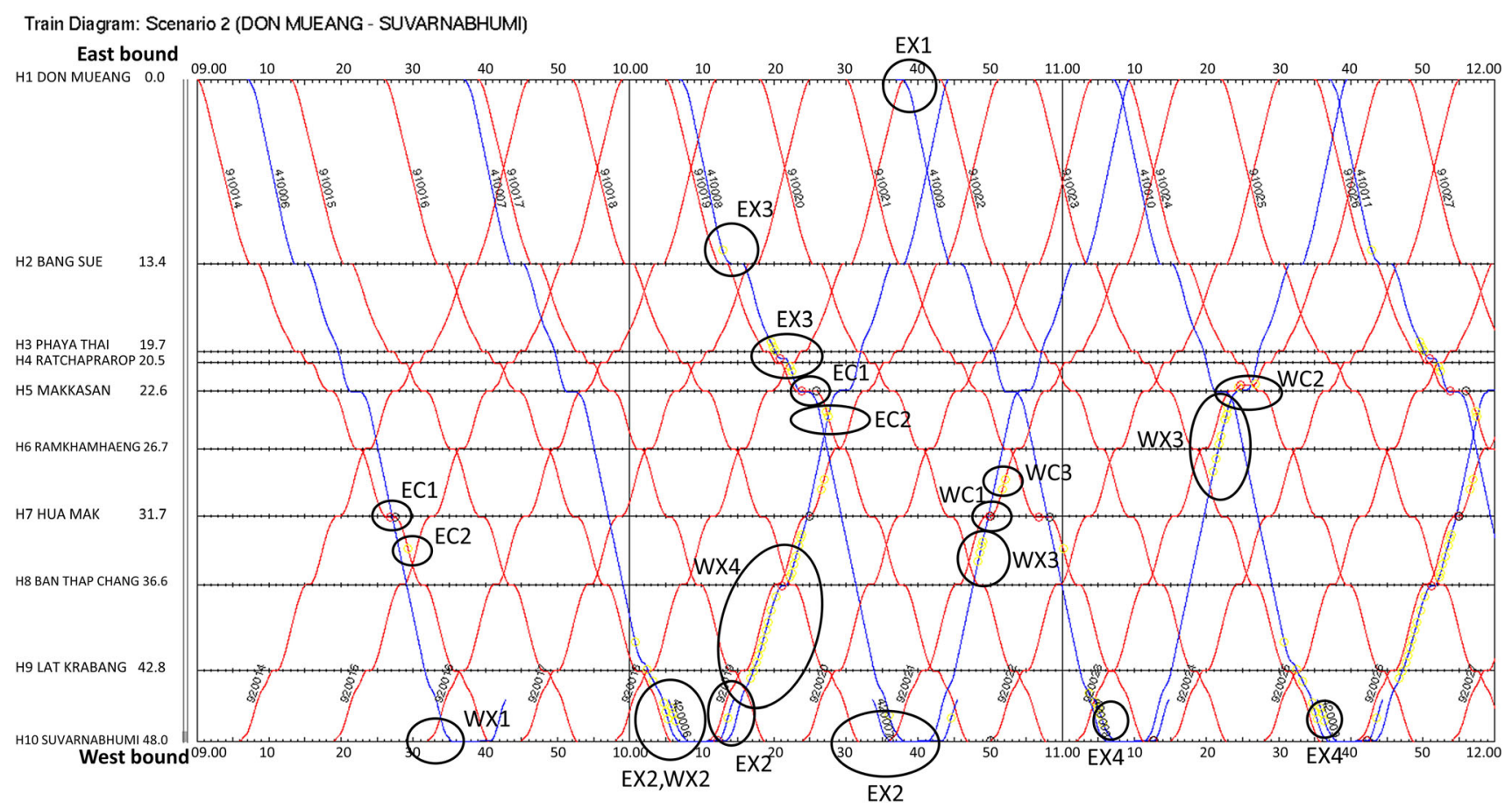

Fig. 6 Time-distance diagram for city and high-speed line during off-peak (S2)

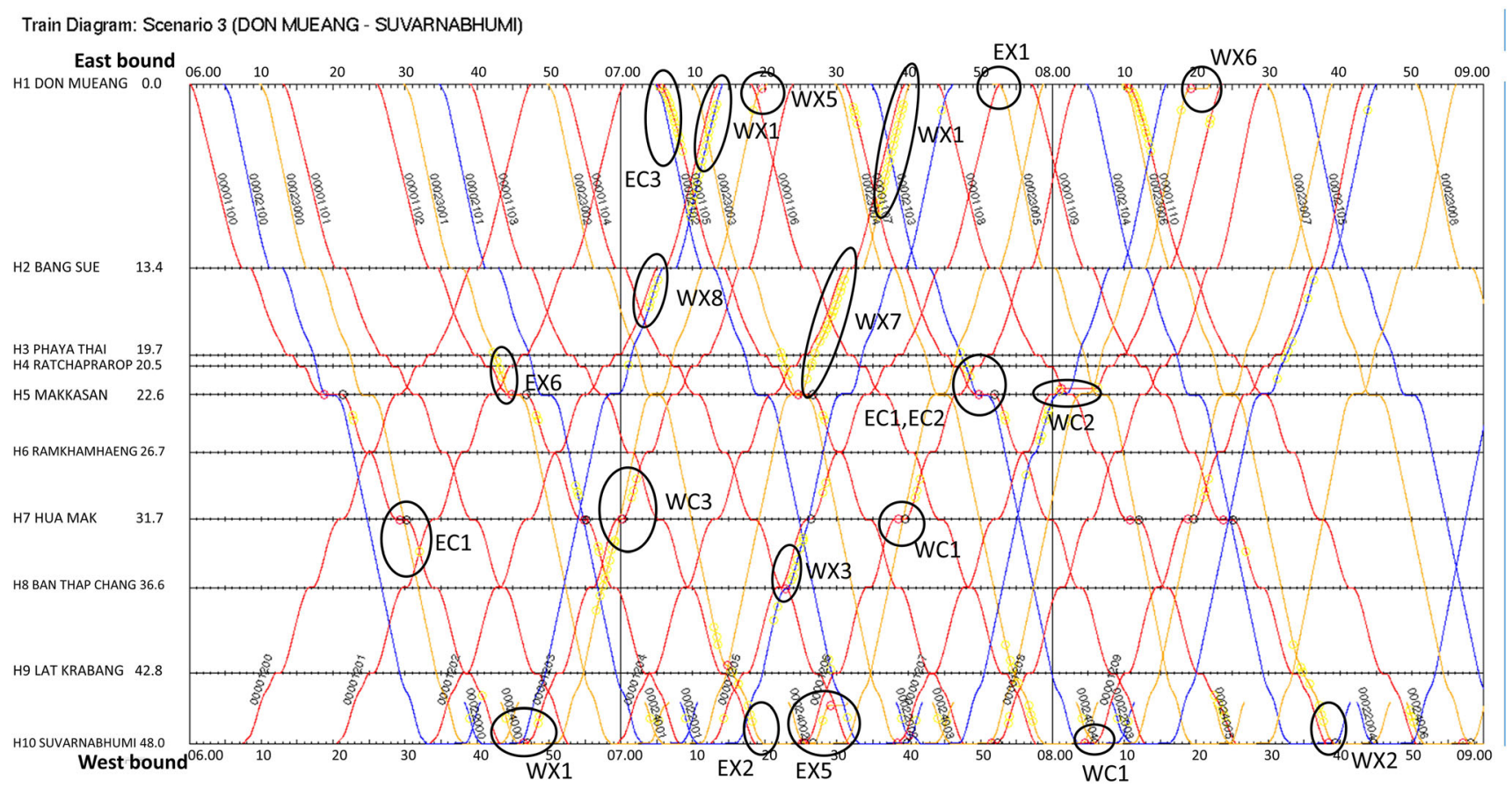

Fig. 7 Time-distance diagram of network train simulation during peak (S3), section Don Mueang-Suvarnabhumi

\subsubsection{The Eastbound Direction (DOM-SVB)}

For the eastbound direction, city trains may need to: (1) have additional dwell time at MAS or HUM Stations in order to let express trains (high-speed train) overtake and pass over (see EC1); (2) reduce running speed when departing from MAS or HUM to allow a safe distance from the overtaking high-speed train in front (see EC2). For the 


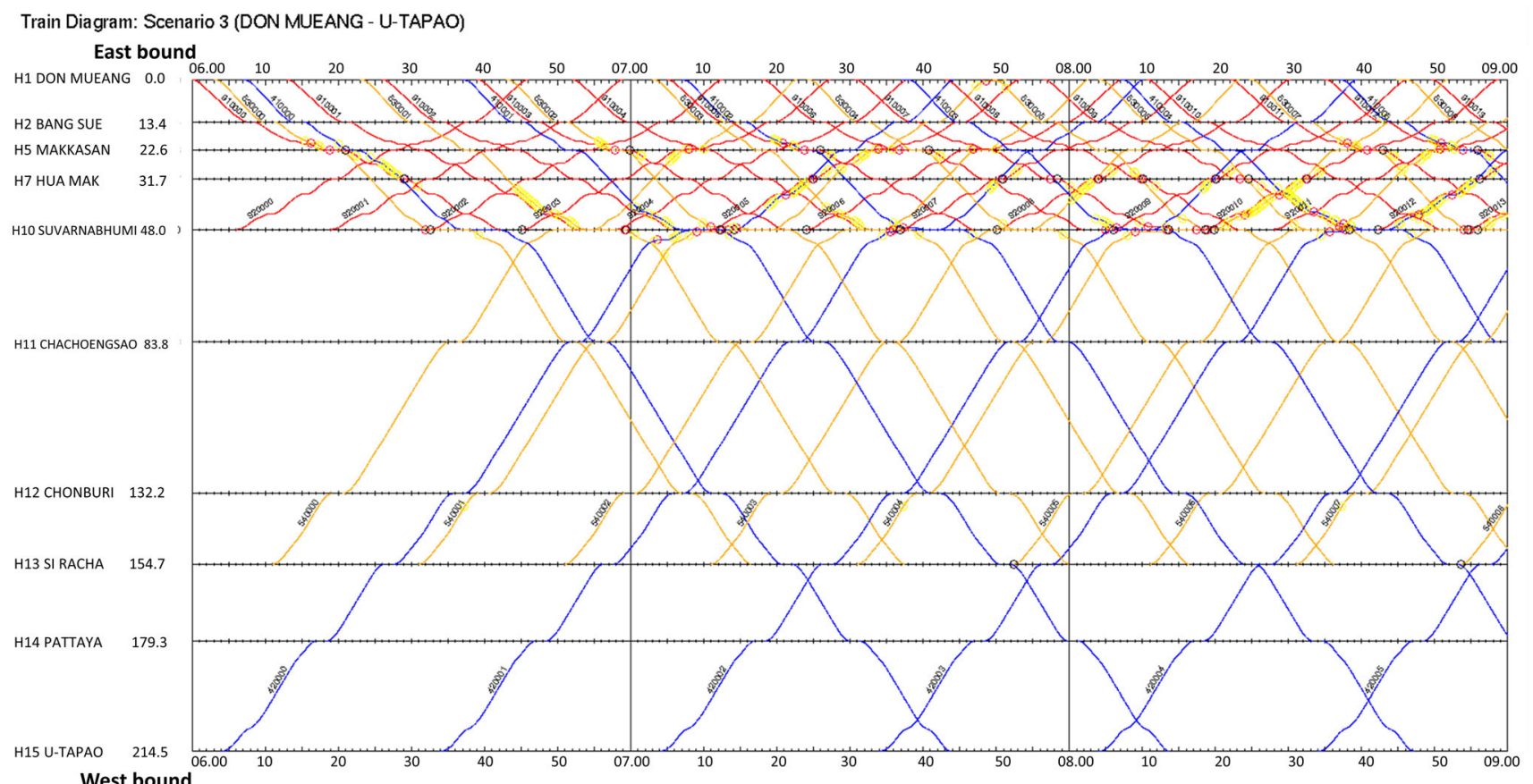

Fig. 8 Time-distance diagram of network train simulation during peak (S3), section Don Mueang-U-Tapao

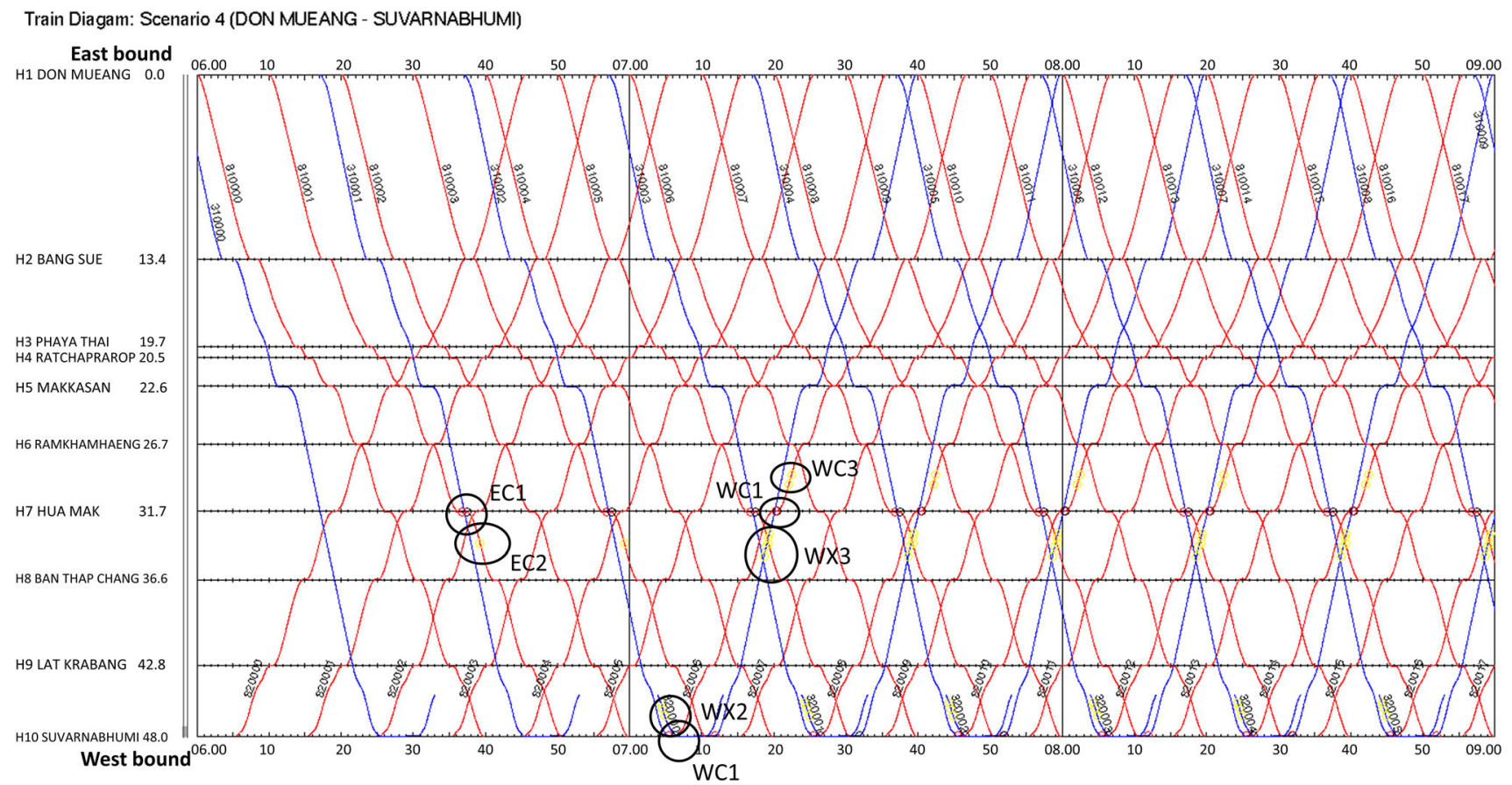

Fig. 9 Time-distance diagram of network train simulation during peak (S4), section Don Mueang-Suvarnabhumi

high-speed train, there will be a late departure at DOM Station (see EX1). With the cross over at DOM Station, the high-speed train needs to let the city line train from the westbound direction enter DOM Station first. When approaching or leaving SVB Station, the high-speed train may need to reduce running speed (see EX2) in order to: (1) provide the safe distance from a city train or high-speed train in front; (2) let the city line train first complete turning 
Table 3 Maximum additional running times for each scenario

\begin{tabular}{|c|c|c|c|c|c|c|c|c|}
\hline \multirow[t]{3}{*}{ Scenario } & \multicolumn{8}{|c|}{ Maximum additional running time (hr:min:s) } \\
\hline & \multicolumn{4}{|l|}{ Eastbound } & \multicolumn{4}{|l|}{ Westbound } \\
\hline & Desiro city & Desiro express & Zefiro HST-1 & Zefiro HST-2 & Desiro city & Desiro express & Zefiro HST-1 & Zefiro HST-2 \\
\hline S-1 & $0: 01: 21$ & 0:00:00 & - & - & $0: 01: 42$ & $0: 00: 33$ & - & - \\
\hline S-2 & 0:02:09 & - & $0: 02: 40$ & - & $0: 02: 18$ & - & 0:05:02 & - \\
\hline S-3 & 0:04:30 & - & $0: 05: 39$ & $0: 12: 57$ & $0: 02: 12$ & - & $0: 12: 34$ & $0: 11: 25$ \\
\hline S-4 & $0: 00: 43$ & - & 0:00:00 & - & 0:00:13 & - & 0:00:31 & - \\
\hline
\end{tabular}

Table 4 Total additional running times in $3 \mathrm{~h}$ for each scenario

\begin{tabular}{|c|c|c|c|c|c|c|c|c|}
\hline \multirow[t]{3}{*}{ Scenario } & \multicolumn{8}{|c|}{ Total additional running time in $3 \mathrm{~h}$ (hr:min:s) } \\
\hline & \multicolumn{4}{|l|}{ Eastbound } & \multicolumn{4}{|l|}{ Westbound } \\
\hline & Desiro city & Desiro express & Zefiro HST-1 & Zefiro HST-2 & Desiro city & Desiro express & Zefiro HST-1 & Zefiro HST-2 \\
\hline S-1 & $0: 20: 15$ & 0:00:00 & - & - & $0: 25: 30$ & $0: 04: 24$ & - & - \\
\hline S-2 & $0: 07: 24$ & - & $0: 10: 46$ & - & $0: 05: 18$ & - & $0: 10: 50$ & - \\
\hline S-3 & $0: 17: 28$ & - & $0: 22: 10$ & $1: 36: 15$ & $0: 07: 51$ & - & $0: 32: 01$ & $0: 25: 59$ \\
\hline S-4 & $0: 06: 27$ & - & 0:00:00 & - & 0:01:57 & - & 0:04:39 & - \\
\hline
\end{tabular}

around, back to the westbound direction. If the high-speed train is scheduled to depart from DOM shortly after the city train (for example, $2 \mathrm{~min}$ ), the following high-speed train needs to reduce running speed when approaching most of the stations before overtaking at MAS Station (see EX3). This is due to the fact that the high-speed train needs to maintain safe distance from the city train in front. The high-speed train needs to have some additional dwell time at SVB Station in order to let the city train and high-speed train from the westbound direction depart first (see EX4).

\subsubsection{The Westbound Direction (SVB-DOM)}

For the westbound direction, the city train may need to: (1) have additional dwell time at HUM and DOM Stations in order to let the high-speed train overtake and pass over (see WC1); (2) have a late departure to let the high-speed train overtake and pass over at MAS Station (see WC2); (3) reduce running speed when departing from HUM to allow a safe distance from the overtaking high-speed train in front (see WC3). The high-speed train may need to reduce speed before approaching MAS and HUM Stations in order to keep a safe distance from the city train (see WX3). In addition, the high-speed train may need to reduce running speed when approaching SVB and DOM Stations to allow a safe distance from the high-speed train eastbound or city train westbound in front (see WX1). There will be a late departure at SVB Station (see EX2, WX2). The late departure affects two high-speed train lines toward both eastbound (out-of-town section) and westbound (in-town section) directions. This is because the city train in front needs first to leave the SVB terminal station and turn back toward the westbound or in-town direction. If the highspeed train is scheduled to depart from SVB shortly after the city line (around $2 \mathrm{~min}$ ), the following high-speed train needs to reduce running speed when approaching most of the stations before overtaking at HUM Station. This is because the high-speed train needs to maintain a safe distance from the city line train in front (WX4).

For peak service operations, there might be more traffic at the DOM and SVB terminal areas (Figs. 7, 8, 9). The example time-distance diagram of the whole network is shown in Fig. 8. At DOM Station area, high-speed train 2 needs to reduce speed when approaching DOM Station from the westbound direction (see WX5). This is in order to let the city train first leave the DOM terminal station; and the high-speed train 2 needs to reduce speed when departing from DOM shortly after the city train: around 1 min (see EC3). After leaving the SVB Station area, highspeed train 2 may need to stop before the crossing turnout to let the city train and high-speed train from the eastbound direction first approach the SVB Station (see EX5). Highspeed train 2 needs to arrive late to let high-speed train 1 turn back toward the eastbound (see WX6). High-speed 


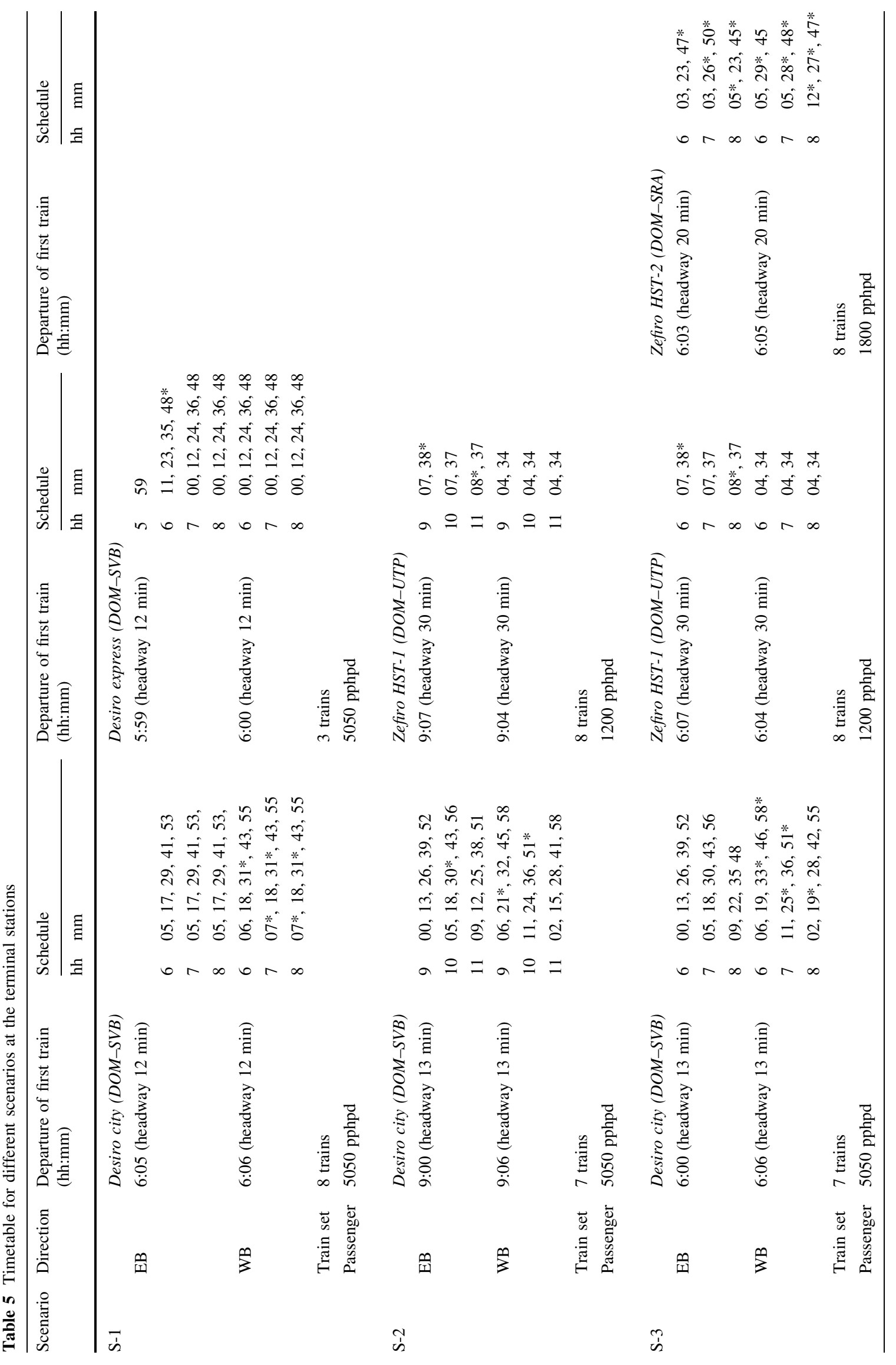




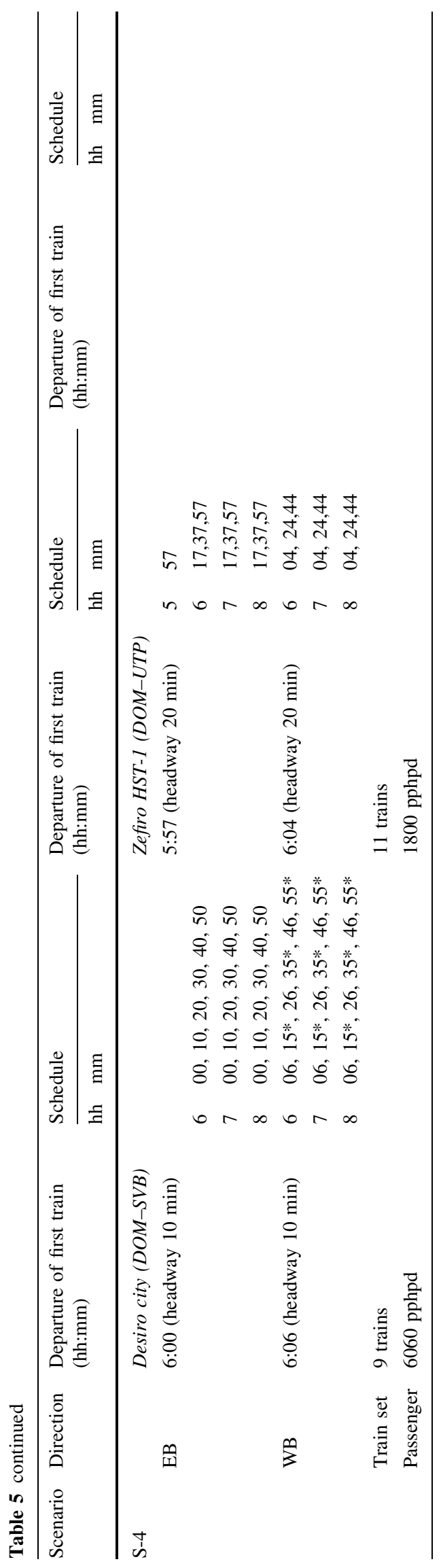

train 2 may need to reduce running speed before approaching and leaving MAS Station in order to keep a safe distance with the city line train (see WX7 and EX6). The high-speed train may need to reduce speed before approaching BSE Station in order to keep a safe distance with the city train (see WX8).

\subsection{Timetable}

Based on the peak and off-peak requirements, a feasible timetable can be proposed, as presented in Table 5. The predefined headways are according to the project requirement. An asterisk (*) indicates a departure time that needs additional time from the predefined headway. By using different departure times at different terminal stations in the network model, the train overtaking operations can be managed with less additional time. However, in the peak service requirement of scenario $\mathrm{S} 3$, several additional running times were found, especially for the HST-2 service (Table 4). With the peak service requirement, an alternative service pattern is proposed, as in scenario 4 (Fig. 9). In this service pattern, less additional running time and fewer high-speed train sets will be needed with enough trips per hour, as shown in Table 5.

\section{Conclusions}

In the present work, rail network operation simulation was used to investigate the operational challenges of the extended ARL line for the three airports connection service. For the mixed-service operation from different stopping stations and train configurations, it becomes difficult to arrange the timetable manually. With the dedicated platform assignment for city trains and high-speed trains at each terminal station, similar train services cannot simultaneously enter and leave any station in order to prevent the blocking time conflict. The microsimulation model proved to be helpful in investigating the situation and constructing a feasible timetable in this case. This simulation model can identify route sections which need special attentions such as speed reductions, extended dwell times, or delayed departures.

In this case study, the timetable for different ARL extended services is proposed. Use of "additional running time" is proposed to evaluate and compare different timetables. Running the city line with a 10 min headway and the high-speed line with a 20 min headway during the peak hours is suggested. The high-speed line should operate only as the HST-1. This configuration results in less train usage, especially fewer HST trains. In addition, we realize that running high-speed trains between the two airports or on the in-town section is not efficient, as this option offers little time saving. There is little time saving in 
using the high-speed train instead of the city train. In contrast, the energy consumption of the high-speed train is about 2-3 times higher than the regular city train. Under the existing layout, there is a major bottleneck for the service around SVB Station area. The layout of the airport extension track needs to be carefully considered, since the SVB Station area has a high risk of disruption. To speed up entering and exiting the SVB tunnel, we have already proposed adding one crossing track just outside the SVB tunnel. It might be worthwhile to explore the possibility of using the city train for the express service and using LKB Station as a high-speed interchange station to reduce traffic around the SVB tunnel station area. It is less than 6 min for the LKB-SVB rail link service. However, it will need an additional platform and services at LKB Station to become the interchange station for both city and high-speed trains, in this case. The findings of the work presented herein are based on the high-speed Zefiro with a 4-km maximum block length and existing city platforms. In this case, only Makasan and Huamak Stations allow the train to pass over. With the modified track layout, pass over stations, block length, and train specifications results are expected to differ, but insights from this study remain generally valid.

Open Access This article is licensed under a Creative Commons Attribution 4.0 International License, which permits use, sharing, adaptation, distribution and reproduction in any medium or format, as long as you give appropriate credit to the original author(s) and the source, provide a link to the Creative Commons licence, and indicate if changes were made. The images or other third party material in this article are included in the article's Creative Commons licence, unless indicated otherwise in a credit line to the material. If material is not included in the article's Creative Commons licence and your intended use is not permitted by statutory regulation or exceeds the permitted use, you will need to obtain permission directly from the copyright holder. To view a copy of this licence, visit http://creativecommons.org/licen ses/by/4.0/.

\section{References}

1. Heathrow Airport (2019) Wikipedia, the free encyclopedia [updated 2019 September 6; cited 2019 September 7]. https://en. wikipedia.org/wiki/Heathrow_Airport

2. Airport Express (MTR) (2019) Wikipedia, the free encyclopedia; 2019 [updated 2019 August 27; cited 2019 September 7]. https:// en.wikipedia.org/wiki/Airport_Express_(MTR)

3. Narita Express (2019) Wikipedia, the free encyclopedia; 2019 [updated 2019 July 22; cited 2019 September 7]. https://en.wiki pedia.org/wiki/Narita_Express

4. Frankfurt Airport long-distance station (2019) Wikipedia, the free encyclopedia; 2019 [updated 2019 September 3; cited 2019 September 7]. https://en.wikipedia.org/wiki/Frankfurt_Airport_ long-distance_station

5. Airport Rail Link (Bangkok) (2019) Wikipedia, the free encyclopedia; 2019 [updated 2019 August 7; cited 2019 September 7]. https://en.wikipedia.org/wiki/Airport_Rail_Link_(Bangkok)
6. Pachl J (2018) Railway operation and control, 4th edn. VTD Rail Publishing

7. Hassannayebi E, Sajedinejad A, Mardani S (2014) Urban rail transit planning using a two-stage simulation-based optimization approach. Simul Model Pract Theory 1(49):151-166

8. Brunger O, Dahlhaus E (2014) Running time estimation. In: Hanson IA, Pachl J (eds) Railway timetabling and operations, 2nd edn. Eurail Press, Hamburg, pp 65-89

9. Hanson IA, Pachl J (eds) (2014) Railway timetabling and operations. Eurail Press

10. Wales J, Marinov M (2015) Analysis of delays and delay mitigation on a metropolitan rail network using event based simulation. Simul Model Pract Theory 1(52):52-77

11. Albrecht T (2009) Automated timetable design for demand-oriented service on suburban railways. Pub Transp 1(1):5-20

12. Grube P, Núñez F, Cipriano A (2011) An event-driven simulator for multi-line metro systems and its application to Santiago de Chile metropolitan rail network. Simul Model Pract Theory 19(1):393-405

13. Motraghi A, Marinov MV (2012) Analysis of urban freight by rail using event based simulation. Simul Model Pract Theory 1(25):73-89

14. Bešinović N, Goverde RMP, Quaglietta E, Roberti R (2016) An integrated micro-macro approach to robust railway timetabling. Transp Res Pt B Methodol 87:14-32

15. Radtke A (2014) Infrastructure modelling. In: Hanson IA, Pachl J (eds) Railway timetabling and operations, 2nd edn. Eurail Press, Hamburg, pp 43-57

16. Watson R, Medeossi G (2014) Simulation. In: Hanson IA, Pachl J (eds) Railway timetabling and operations, 2nd edn. Eurail Press, Hamburg, pp 191-215

17. Nash A, Huerlimann D (2004) Railroad simulation using OpenTrack. WIT Trans Built Environ 74

18. Keiji K, Naohiko H, Shigeru M (2015) Simulation analysis of train operation to recover knock-on delay under high-frequency intervals. Case Stud Transp Policy 3(1):92-98

19. Ljubaj I, Mlinarić T, Radonjić D (2017) Proposed solutions for increasing the capacity of the Mediterranean Corridor on section Zagreb-Rijeka. Proc Eng 192:545-550

20. Pouryousef H, Lautala P (2015) Hybrid simulation approach for improving railway capacity and train schedules. J Rail Transp Plan Manag 5(4):211-224

21. Pitalänen J-P, Capek K (2013) The improvement of helsinki railway yard's functionality. In: 5th international seminar on railway operations modelling and analysis; Technical University of Denmark. International Association of Railway Operations Research

22. Botte M, D'Acierno L (2018) Dispatching and rescheduling tasks and their interactions with travel demand and the energy domain: models and algorithms. Urban Rail Trans 4(4):163-197

23. Weerawat $\mathrm{W}$, Boonchai $\mathrm{T}$ (2018) Simulation modeling in metro operations pattern analysis. Thai J Sci Technol 7(3):293-306

24. Weerawat W, Chumkad K (2018) A new operations approach for Bangkok Metro Green Line using short turn operation patterns. J Rail Transp Plan Manag 8(3-4):207-219

25. Aly MHF, Hemeda H, El-sayed MA (2016) Computer applications in railway operation. Alex Eng J 55(2):1573-1580

26. Powell JP, Fraszczyk A, Cheong CN, Yeung HK (2016) Potential benefits and obstacles of implementing driverless train operation on the Tyne and Wear Metro: a simulation exercise. Urban Rail Trans 2(3-4):114-127 
27. The high-speed rail linking three airport project feasibility study (2017) Bangkok: Asian Engineering Consultants Corporation Limited

28. High-speed rail in Thailand (2019) Wikipedia, the free encyclopedia; 2019 [updated 2019 October 27; cited 2019 October 30]. https://en.wikipedia.org/w/index.php?title=High-speed_rail_in_ Thailand\&oldid $=923294245$
29. The high-speed rail linking three airport project request for proposal volume 2: SRT's requirements, Volume 2/1: the rail-related works of the project, Phase 2: operation-maintenance, Part 2: operation concepts. Bangkok: Asian Engineering Consultants Corporation Limited; 2018 